\title{
Effects of Indoor Rowing Exercise on the Body Composition and the Scoliosis of Visually Impaired People: A Preliminary Study
}

\author{
Ka-Young Shin, MD, Eun-Hi Choi, MD, PhD, Jong-Youb Lim, MD, Ah-Ra Cho, MD, Young-Ho Lim, MD
}

Department of Physical Medicine and Rehabilitation, Hallym University Chuncheon Sacred Heart Hospital, Hallym University College of Medicine, Chuncheon, Korea

Objective To evaluate the effects of rowing exercise on body composition, laboratory data, fitness and scoliosis in visually impaired people. The majority of visually impaired people do not participate in active sports due to efficiency and safety issues. Rowing is a safe whole-body exercise with aerobic and anaerobic components.

Methods Twenty subjects were recruited from among those admitted to a facility for visually impaired people (16 men and 4 women). Laboratory data, body composition, physical fitness, Cobb's angle, and fall index were checked before and after 6 weeks ( 5 days a week) of indoor rowing using Concept2 Model E.

Results After the training, fat mass and total body fat percent decreased significantly. In the fitness test, back strength and trunk flexion score increased significantly. Laboratory data showed significant increases in serum protein and albumin and decreases in low-density lipoprotein (LDL) cholesterol. There were 9 subjects with scoliosis and after the training Cobb's angle decreased by $1.11^{\circ} \pm 1.55^{\circ}$, though this was not statistically significant. Conclusion Visually impaired people frequently have abnormal body composition, low physical fitness, and scoliosis. A rowing exercise program can be helpful, with a positive effect on body composition and physical fitness; however, with respect to scoliosis, we need an earlier intervention program in visually impaired people.

Keywords Visual impairment, Rowing, Body composition, Scoliosis

\section{INTRODUCTION}

The visually impaired elderly have a high level of low-

Received June 3, 2014; Accepted October 27, 2014

Corresponding author: Eun-Hi Choi

Department of Physical Medicine and Rehabilitation, Hallym University Chuncheon Sacred Heart Hospital, Hallym University College of Medicine, 77 Sakju-ro, Chuncheon 200-704, Korea

Tel: +82-33-240-5299, Fax: +82-33-241-8063, E-mail: choi.eunhi@gmail.com

(c) This is an open-access article distributed under the terms of the Creative Commons Attribution Non-Commercial License (http://creativecommons. org/licenses/by-nc/4.0) which permits unrestricted noncommercial use, distribution, and reproduction in any medium, provided the original work is properly cited.

Copyright $\odot 2015$ by Korean Academy of Rehabilitation Medicine density lipoprotein (LDL) cholesterol and high prevalence of low body weight [1]. Visually impaired students are vulnerable to obesity and fatigue [2] and increasing obesity with aging [3]. These studies showed opposite results that may be due to age difference. In addition, postural abnormality due to visual impairment can lead to scoliosis [4], static and dynamic imbalance [5], and musculoskeletal disorder or low back pain [6]. Visually impaired women show decreased femur bone density [7]. Despite these health problems, the majority of visually impaired people do not participate in active sports due to efficiency and safety issues [8]. 
The benefits of regular physical activity for improving physical and mental health are well known. Adequate physical activity can reduce cardiovascular disease, diabetes mellitus, hypertension, and obesity [9], and can increase muscle function and bone mass.

Among the numerous physical activities, rowing is a whole-body strength-endurance sport with an aerobic and anaerobic component [10]. Dynamic balance control is reportedly disruptive under visual deprivation conditions and anatomic deformation results in asymmetric muscle strength [11]. Thus, rowing exercise that requires well-balanced symmetric movement might be helpful for the visually impaired people, especially for those with scoliosis.

The aims of this study were to investigate the negative effect of visual impairment on laboratory data, body composition, physical fitness, and scoliosis as well as to evaluate the therapeutic effects of rowing exercise for the visually impaired.

\section{MATERIALS AND METHODS}

\section{Subjects}

Subjects $(n=20)$ were recruited from among those admitted to a facility for visually impaired people; 16 were men and 4 women; mean age was $25.95 \pm 10.98$ years (Table 1). All subjects could walk independently under supervision. All subjects had no previous history of regular exercise that included aerobic and anaerobic elements. We excluded people who had disability or injury of upper or lower extremities, history of convulsion, mental retardation sufficiently severe to preclude learning to row, or cardiopulmonary insufficiency. Blood laboratory data, body composition, physical fitness test, whole spine Xray, and Tetrax posturography were checked before and after 6 weeks of rowing exercise training. All subjects were asked to maintain routine nutrition and lifestyle during training. This study was approved by the Clinical Trial Ethics Committee of the Hallym University of College of Medicine. All patients provided written informed consent.

\section{Laboratory data}

Blood sampling was conducted to gather laboratory data before and after 6 -week rowing exercise training. Laboratory data included hemoglobin, protein, albumin, total cholesterol, triglyceride (TG), high-density lipoprotein (HDL) cholesterol, and LDL cholesterol.

\section{Body composition data}

Dual-energy X-ray absorptiometry (Lunar Prodigy, GE, Madison, WI, USA) was used to measure body composition before and after 6 -week rowing exercise training. Body composition was comprised of android/gynoid ratio, fat mass, lean mass, bone marrow content, total body fat percent, body mass index (BMI), and body weight.

\section{Physical fitness test}

The physical fitness test was composed of grip strength, back strength, trunk flexion, trunk extension, and vertical jump using physical fitness measurement equipment (Takei Scientific Instruments Co. Ltd., Niigata, Japan). Grip strength (kg) and back strength (kg) were measured to evaluate static strengthening. The flexibility item was

Table 1. General characteristics $(n=20)$

\begin{tabular}{|cc|}
\hline \multicolumn{1}{|c|}{ Parameter } & Value \\
\hline Age (yr) & $25.95 \pm 10.98$ \\
\hline Sex (man:woman) & $16: 4$ \\
\hline Body weight $(\mathrm{kg})$ & $69.63 \pm 25.46$ \\
\hline Height $(\mathrm{cm})$ & $163.12 \pm 10.37$ \\
\hline Grade of visual disability & \\
\hline 1 & 10 \\
\hline 2 & 3 \\
\hline 3 & 2 \\
\hline 4 & 1 \\
\hline 5 & 2 \\
\hline 6 & 2 \\
\hline Etiology & \\
\hline Congenital & 6 \\
\hline Preterm birth & 2 \\
\hline Retinitis pigmentosa & 2 \\
\hline Glaucoma & 1 \\
\hline Meningitis & 2 \\
\hline Trauma & 2 \\
\hline Unknown & 5 \\
\hline Visual acuity & \\
\hline Blindness & 5 \\
\hline Low vision & 15 \\
\hline
\end{tabular}

Values are presented as mean \pm standard deviation or number. 
trunk flexion $(\mathrm{cm})$ and trunk extension $(\mathrm{cm})$. The swiftness item was vertical jump $(\mathrm{cm})$. Results of the physical fitness test were converted to the percentage of age/sexmatched normal data. Sources for grip and back strength, trunk extension and vertical jump are "Standard Values for Physical Strength of the Japanese 2000" by the Standard Physical Strength Survey Team, Tokyo Metropolitan University; source for trunk flexion is "The Survey of National Physical Fitness 2011" by the Korea Institute of Sport Science, Korea Sports Promotion Foundation.

For testing back strength, the subject was asked to stand upright on the base of the dynamometer with feet shoulder-width apart, arms straight, and fingers extended downward as far as possible on the front of thighs. The bar is then attached to the chain so that it is 1 to 2 inches below fingertips. Then the subject bends forward slightly and grasps the bar. The subject should hold his or her head upright and look straight ahead. Lifting the bar steadily, the subject is required to keep legs straight and feet flat on the base of the dynamometer.

For testing trunk flexion, the subject sits with knees fully extended so that the bottoms of the feet are against the surface of the flex box. Arms are extended forward, with one hand placed on the top of the other. With the instructor holding the subject's knees straight, the subject steadily reaches as far forward as possible and maintains this position for 3 seconds.

Trunk extension measurement requires 2 people in addition to the subject: one measurer and one assistant. The subject lies face down on the floor, clasps hands behind the waist and holds the legs apart so that the toes are about $45 \mathrm{~cm}$ from each other. The assistant holds on the back of the thighs to fix the position. The subject raises his or her chin as high as possible by gradually bending upper body backward. The measurer measures the distance of the highest position of the chin from the floor.

For the grip strength measurement, the subject stands upright and squeezes the dynamometer as tightly as possible.

For testing vertical jump, the subject puts on the belt around his or her waist tightly so as not to be shaken provide the main body of Jump-MD. Then, stand on the center of the rubber plate and jump straight up.

All tests were performed twice and the greater values of the 2 results for each measurement were selected.

\section{Tetrax posturography}

Using Tetra-ataxiametric posturography (Tetrax, Sunlight Medical Ltd., Tel-Aviv, Israel), the fall index was checked before and after 6 weeks of rowing exercise training.

\section{Radiologic data}

Whole spine X-rays were taken to measure Cobb's angle before and after 6 -week rowing exercise training.

\section{Exercise program}

Concept2 rowing model E (Concept2 Inc., Morrisville, VT, USA) was used for 6 weeks of rowing training (Fig. 1). The rowing machine was set up 5 days a week; each session included a 10-minute warm-up, a 20-minute rowing exercise, and a 10-minute cooling-down period. The subjects were given instructions on how to use the rowing machine prior to the exercise program. Each subject was asked to row for 1 minute with maximal effort to measure exercise intensity. Individual's maximal exercise capacity revealing maximum muscular strength for 1 minute was regarded as 1 repetition maximum (RM). Exercise intensity was $40 \%-50 \%$ of $1 \mathrm{RM}$ during the 2 -week adaptation period and 50\%-60\% during next 4 weeks. The subjects rowed at a self-selected stroke rate and resistance level. As all subjects were beginners, the commonly chosen resistant level was from 3 to 5 . Concept 2 rowing model $\mathrm{E}$ has a monitor that provides distance, speed, pace, calories, and watts for each workout, and it was helpful for controlling and supervising each session. The assistant could supervise the entire exercise process including get-

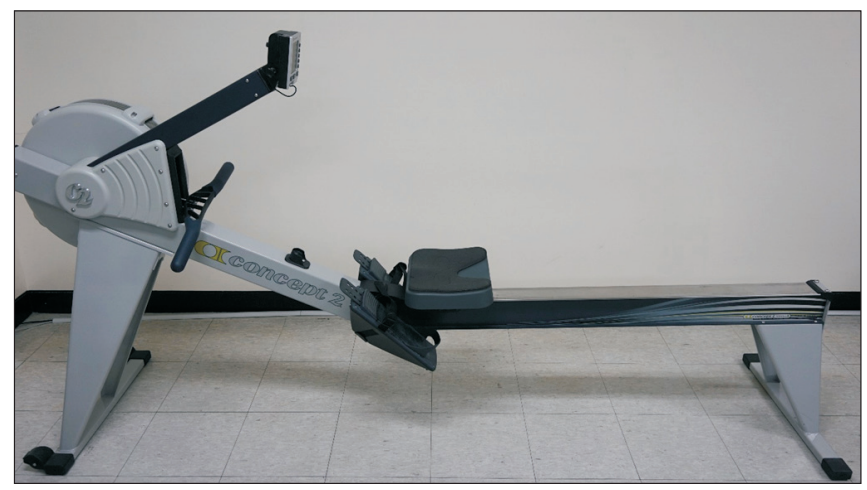

Fig. 1. Concept2 rowing model E (Concept2 Inc., Morrisville, VT, USA). 
ting on and off the rowing machine. Blood pressure and heart rate were checked before and after the exercise to monitor abnormal cardiopulmonary response.

\section{Data analysis}

Data were uploaded into the SPSS ver. 21.0 (IBM SPSS, Armonk, NY, USA). Descriptive statistics were used to describe the subjective characteristics. A paired t-test was performed to compare the health status before and after the exercise. $\mathrm{p}<0.05$ was adopted as the level of statistical significance.

\section{RESULTS}

\section{Laboratory data}

Initially, none of the subjects was anemic; one subject had low protein, and 3 subjects had low albumin levels. Five subjects had LDL-cholesterol levels that were above the upper normal limit.

After the training, the protein and albumin had in- creased significantly, while the LDL had decreased significantly. Hemoglobin, total cholesterol, and TG levels decreased, while HDL-cholesterol increased; however, the differences were not statistically significant (Table 2).

\section{Body composition}

Using healthy body fat range chart based on National Institutes of Health/World Health Organization guidelines that categorize ranges of body fat percentages, initially, in terms of total body fat percentage, 8 subjects were normal, 1 was overfat, and 11 were obese. According to the criteria determined by the Korean Society for the Study of Obesity, BMI of $\geq 23$ indicates the overweight, and BMI of $<18.5$ indicates underweight. BMI for the subjects showed that 5 were normal, 5 were underweight, and 10 were obese. Fat mass and total body fat percentage decreased significantly after the training. Lean body mass and bone marrow content increased after the training, though not statistically significantly (Table 3 ).

Table 2. Laboratory data changes after 6 weeks rowing exercise $(n=20)$

\begin{tabular}{lccc}
\multicolumn{1}{c}{ Variable } & Initial & After rowing exercise & p-value \\
\hline Hemoglobin (g/dL) & $14.86 \pm 0.93$ & $14.85 \pm 0.97$ & 0.865 \\
Protein (g/dL) & $6.91 \pm 0.34$ & $6.92 \pm 0.34$ & $0.003^{*}$ \\
Albumin (g/dL) & $4.16 \pm 0.21$ & $4.35 \pm 0.19$ & $0.000^{*}$ \\
Cholesterol (mg/dL) & $170.65 \pm 30.12$ & $164.65 \pm 6.26$ & 0.142 \\
Triglyceride (mg/dL) & $88.10 \pm 34.32$ & $86.95 \pm 31.65$ & 0.749 \\
HDL-cholesterol (mg/dL) & $53.00 \pm 12.55$ & $53.85 \pm 13.81$ & 0.591 \\
\hline LDL-cholesterol (mg/dL) & $104.45 \pm 31.28$ & $95.20 \pm 5.89$ & $0.005^{*}$ \\
\hline
\end{tabular}

Values are presented as mean \pm standard deviation.

HDL, high density lipoprotein; LDL, low density lipoprotein.

${ }^{*} \mathrm{p}<0.05$.

Table 3. Body composition changes after 6 weeks rowing exercise $(n=20)$

\begin{tabular}{lccc}
\hline \multicolumn{1}{c}{ Variable } & Initial & After rowing exercise & p-value \\
\hline Android/Gynoid ratio & $0.99 \pm 0.23$ & $0.99 \pm 0.23$ & 1.000 \\
\hline Fat mass (kg) & $22.26 \pm 14.66$ & $21.34 \pm 14.83$ & $0.010^{*}$ \\
\hline Lean body mass $(\mathrm{kg})$ & $43.08 \pm 11.74$ & $43.57 \pm 11.96$ & 0.372 \\
\hline Bone marrow content $(\mathrm{kg})$ & $2.48 \pm 0.53$ & $2.53 \pm 0.59$ & 0.085 \\
\hline Total body fat percentage (\%) & $31.14 \pm 11.63$ & $29.74 \pm 11.92$ & $0.006^{*}$ \\
\hline Body weight $(\mathrm{kg})$ & $69.63 \pm 25.46$ & $69.06 \pm 25.97$ & 0.193 \\
\hline Body mass index $\left(\mathrm{kg} / \mathrm{m}^{2}\right)$ & $25.66 \pm 7.62$ & $25.51 \pm 7.81$ & 0.328 \\
\hline
\end{tabular}

Values are presented as mean \pm standard deviation.

${ }^{*} \mathrm{p}<0.05$. 
Table 4. Fitness changes after 6 weeks rowing exercise $(n=20)$

\begin{tabular}{|cccc}
\hline Variable & Initial & After rowing exercise & p-value \\
\hline Grip strength (\%) & & & \\
\hline Right & $44.31 \pm 19.08$ & $45.47 \pm 20.93$ & 0.420 \\
\hline Left & $49.45 \pm 23.98$ & $49.23 \pm 22.03$ & 0.962 \\
\hline Back strength (\%) & $31.58 \pm 16.43$ & $42.29 \pm 18.50$ & $0.008^{*}$ \\
\hline Trunk flexion (\%) & $34.92 \pm 71.68$ & $71.35 \pm 70.08$ & $0.007^{*}$ \\
\hline Trunk extension (\%) & $23.71 \pm 15.30$ & $29.33 \pm 18.08$ & 0.050 \\
\hline Vertical jump (\%) & $28.39 \pm 21.51$ & $33.89 \pm 16.87$ & 0.121 \\
\hline Fall index & $72.10 \pm 25.79$ & $67.50 \pm 25.33$ & 0.381 \\
\hline
\end{tabular}

Values are presented as mean \pm standard deviation.

${ }^{*} \mathrm{p}<0.05$.

\section{Physical fitness test}

Initially, comparing age/sex-matched normal data, the grip strengths were $44.31 \% \pm 19.08 \%$ (right) and $49.45 \% \pm 23.98 \%$ (left), and the back strength was $31.58 \% \pm 16.43 \%$; while the trunk flexion was $34.92 \% \pm$ $71.68 \%$, the trunk extension was $23.71 \% \pm 15.30 \%$, and the vertical jump was $28.39 \% \pm 21.51 \%$ (Table 4 ). In addition, the visually impaired subjects seemed to have low physical fitness levels, as compared with the general population, especially in back strength, trunk flexion/extension, and vertical jump.

After training, back strength and trunk flexion increased significantly. Grip strength of right hand, the trunk extension, and the vertical jump also increased, but not significantly.

\section{Tetrax posturography}

Based on the initial fall index (risk of fall assessment), 14 subjects were at high risk of falling and 4 were at medium risk, while only 2 were at minimal risk. After 6 weeks of rowing training, 4 subjects had moved to a lower risk group. In all subjects' results, fall index decreased by $4.60 \pm 5.12$ points, but this result was not statistically significant (Table 4).

\section{Radiology}

The 9 scoliosis patients showed an initial Cobb's angle of $14.20^{\circ} \pm 5.38^{\circ}$. After the training, this decreased by $1.11^{\circ} \pm 1.55^{\circ}$, but this result was not statistically significant. Nevertheless, 6 patients showed decreased Cobb's angle after 6 -week rowing training.

\section{DISCUSSION}

All kinds of aerobic exercise programs have positive effects on visually impaired people; however, there are limitations to their participation in these activities due to safety issues. Therefore, it is necessary to expand selfexercise fields with safety for the visually impaired $[12,13]$. Due to the involvement of numerous muscles and the requirement of skilled coordination between the upper and lower extremities, rowing is a good exercise in terms of balance and efficiency. In addition, rowing exercise can be performed steadily under fixed conditions without further intervention, and it is possible for the users to stop rowing safely whenever required. Thus rowing exercise is considered a safe and effective activity for the visually impaired people.

Previous studies reported that the elderly visually impaired have low body weight [1] while the younger visually impaired are prone to obesity [2]. In this study, 5 subjects showed low body weight (mean age, 19.4 years; mean BMI, $17.12 \pm 0.69 \mathrm{~kg} / \mathrm{m}^{2}$ ) and 10 subjects showed obesity (mean age, 26.3 years; mean BMI, $31.46 \pm 6.27 \mathrm{~kg} /$ $\mathrm{m}^{2}$ ). Most subjects have problem of either low or high body weight despite relatively young age.

Visually impaired elders show a high level of LDL cholesterol [1]. According to the Korean Statistical Information Service published in 2012, the prevalence of high LDL ( $>140 \mathrm{mg} / \mathrm{dL}$ ) was $29.49 \%$ among the whole population, and that of the under 30 years old age group was $12.74 \%$. The same study also showed that rate of high total cholesterol (defined as total cholesterol over 200 $\mathrm{mg} / \mathrm{dL}$ ) was $11.13 \%$ among the whole population, and it was $3.6 \%$ among the under 30 years old age group. In 
our study, the number of subjects in the under 30 years old age group was 15 of the 20 group members. Out of 20 subjects, 5 people had markedly high LDL (mean $146.60 \pm 14.74 \mathrm{mg} / \mathrm{dL}$ ), and 4 of these were under 30 years old. There were 3 people who showed high cholesterol level (mean $221.67 \pm 9.71 \mathrm{mg} / \mathrm{dL}$ ), and all of them were under 30 years old. Neither low HDL nor high TG was found in any subjects. In the current study, we found high prevalence of abnormal lipid profile in the visually impaired people, as compared with normal population; however, the sample size was too small.

A previous study divided obese children with mental retardation into a rowing exercise group and a treadmill exercise group and trained them for 12 weeks. The laboratory data showed a positive effect on total cholesterol, triglyceride, HDL cholesterol, and LDL cholesterol [14]. Similarly, in our study most visually impaired people showed increment in protein and albumin, but decrement in LDL cholesterol after 6 weeks of rowing exercise training.

According to Park et al. [14], body weight and fat mass decreased, lean body mass increased in both, rowing exercise and treadmill groups. We likewise checked body composition and found 10 subjects were obese and 5 were underweight. After 6 weeks of rowing exercise training, fat mass and total body fat percentage decreased significantly. Lean body mass of 15 subjects and bone marrow content of 14 subjects had increased, but not significantly. It was difficult to observe significant change and improvement of sarcopenia due to the short exercise period. We expect that these positive effects of the rowing exercise program on blood lipid and body composition could be related to reduction of cardiovascular risk. In addition, rowing exercise produced significant improvements in back strength and trunk flexion, which are strength and flexibility parameters.

It was reported that visually impaired children have high frequency of spinal deformity with a radiologic aspect of structural scoliosis, as compared with healthy control children [4]. The traditional therapeutic regimen for the prevention of scoliosis progression includes exercises, bracing, and surgery [15]. A review of the literature of exercise therapy for the treatment of adolescent idiopathic scoliosis found poor quality of evidence to support the efficacy of exercise therapy [16]. In this study, we found 9 scoliosis patients among 20 subjects by whole spine X-ray, and after 6-week rowing exercise training, changes of the Cobb's angle were not significant. Screening test of scoliosis for early detection and intervention can reduce the risk of curve progression [17]; thus, an early screening and intervention program is required for the visually impaired people to minimize musculoskeletal deformity.

Low back pain is a common problem among rowers. Caldwell et al. [18] suggested that high level of lumbar flexion during the drive phase of the rowing stroke causes a potential injury to erector spinae muscle. Bilateral asymmetries during the rowing stroke, particularly at the hip, are highly related to the lumbar-pelvic kinematics [19]. Incremental rise of frontal plane angular displacement in the lumbar spine during rowing is associated with spinal kinematics [20]. In spite of these concerns, musculoskeletal complication, especially back pain, was not observed in this study. Therefore, it can be concluded that exercise intensity control for appropriate exercise level and awareness of adverse effect on musculoskeletal system of rowing exercise would be helpful to prevent injury.

The possible limitations of the study include small sample size, the lack of a control group and the short training period. However, despite the short period (6 weeks) of training, statistically significant changes in body composition and physical fitness were found.

Further study would be required to recruit a larger visually impaired group and a control group for a longer training duration.

In conclusion, visually impaired people frequently have abnormal body composition, low physical fitness level, and scoliosis. Therefore, systemic inspection of body composition and physical fitness and early screening of scoliosis are needed. Fortunately, a rowing exercise program can be a safe and helpful exercise activity with positive effects on body composition and physical fitness. However, with respect to scoliosis, earlier screening and intervention programs are required for visually impaired people.

\section{CONFLICT OF INTEREST}

No potential conflict of interest relevant to this article was reported. 


\section{ACKNOWLEDGMENTS}

This research was financially supported by the Ministry of Knowledge Economy (MKE), Korea Institute for Advancement of Technology (KIAT) and Kangwon Leading Industry Office through the Leading Industry Development for Economic Region. The funders had no role in study design, data collection and analysis, decision to publish, or preparation of the manuscript.

\section{REFERENCES}

1. Steinman BA, Vasunilashorn S. Biological risk of older adults with visual impairments. J Nutr Health Aging 2011;15:296-302.

2. Paek DH, Lee IK. The current situations and perception of physical education in special schools for students with visual impairments. J Adapt Phys Act Exerc 2007;15:91-113.

3. Lee YC, Choi MR, Jeoung BJ. Prevalence of obesity in students with intellectual disability and visual impairment at special school. J Korean Phys Educ Assoc Girl Woman 2011;25:195-205.

4. Catanzariti JF, Salomez E, Bruandet JM, Thevenon A. Visual deficiency and scoliosis. Spine (Phila Pa 1976) 2001;26:48-52.

5. Giagazoglou P, Amiridis IG, Zafeiridis A, Thimara M, Kouvelioti V, Kellis E. Static balance control and lower limb strength in blind and sighted women. Eur J Appl Physiol 2009;107:571-9.

6. Jones GC, Crews JE, Danielson ML. Health risk profile for older adults with blindness: an application of the International Classification of Functioning, Disability, and Health framework. Ophthalmic Epidemiol 2010;17:400-10.

7. Uusi-Rasi K, Sievaen H, Rinne M, Oja P, Vuori I. Bone mineral density of visually handicapped women. Clin Physiol 2001;21:498-503.

8. Chen CC, Lin SY. The impact of rope jumping exercise on physical fitness of visually impaired students. Res Dev Disabil 2011;32:25-9.

9. US Department of Health and Human Services. Physical activity and health: a report of the Surgeon Gen- eral. Atlanta, GA: Department of Health and Human Services; 1996.

10. Mastu J, Juima J, Juima T. Monitoring of performance and training in rowing. Sports Med 2005;35:597-617.

11. Kuo FC, Wang NH, Hong CZ. Impact of visual and somatosensory deprivation on dynamic balance in adolescent idiopathic scoliosis. Spine (Phila Pa 1976) 2010;35:2084-90.

12. Park JJ, Kim IK, Park HK, Kim SS. The effect of aerobic exercise program on cardiorespiratory function of individuals with visual disability. J Adapt Phys Act Exerc 2001;9:117-29.

13. Han DY, Seo TB, Lee DH, Byun KS, Jeong IG, Lee HH, et al. Analysis on ventilatory threshold and muscle fatigue in an adolescent with blindness during cycle ergometer exercise. J Sport Leis Stud 2009;38:709-18.

14. Park KY, Kim HC, Kim YB, Lee YA, Jeong YT, Kim DW. Analysis of body composition, blood lipid and Ghrelin concentration of obese mentally weak children according to exercise execution of rowing machine and treadmill. J Rehabil Res 2012;16:225-46.

15. Kotwicki T, Chowanska J, Kinel E, Czaprowski D, Tomaszewski M, Janusz P. Optimal management of idiopathic scoliosis in adolescence. Adolesc Health Med Ther 2013;4:59-73.

16. Mordecai SC, Dabke HV. Efficacy of exercise therapy for the treatment of adolescent idiopathic scoliosis: a review of the literature. Eur Spine J 2012;21:382-9.

17. Grivas TB, Wade MH, Negrini S, O'Brien JP, Maruyama T, Hawes MC, et al. SOSORT consensus paper: school screening for scoliosis. Where are we today? Scoliosis 2007;2:17.

18. Caldwell JS, McNair PJ, Williams M. The effects of repetitive motion on lumbar flexion and erector spinae muscle activity in rowers. Clin Biomech (Bristol, Avon) 2003;18:704-11.

19. Buckeridge E, Hislop S, Bull A, McGregor A. Kinematic asymmetries of the lower limbs during ergometer rowing. Med Sci Sports Exerc 2012;44:2147-53.

20. Wilson F, Gormley J, Gissane C, Simms C. The effect of rowing to exhaustion on frontal plane angular changes in the lumbar spine of elite rowers. J Sports Sci 2012;30:1481-9. 